\title{
Effect of Single Nucleotide Polymorphism of Endothelial Differentiation G-Protein Coupled Receptor 1 (EDG1) Gene on Marbling Score in Hanwoo
}

\author{
Sung-Chul Shin and Eui-Ryong Chung* \\ Division of Animal Science and Resources, Sangji University, Wonju 220-702, Korea
}

\begin{abstract}
Marbling (intramuscular fat) is the most economically important meat quality trait in Hanwoo (Korean cattle). The endothelial differentiation G-protein coupled receptor 1 (EDG1) gene, involved in blood vessel formation, is located within the genomic region of a quantitative trait locus (QTL) for marbling on bovine chromosome 3. Thus, the EDG1 gene can be considered as a positional and functional candidate gene for meat quality in beef cattle. This study aimed to identify single nucleotide polymorphisms (SNPs) in the EDG1 gene and to evaluate their associations with carcass traits in Hanwoo population. We have sequenced a fragment of 5'-UTR of the EDG1 gene and identified one SNP. Genotyping of the g.166A>G SNP marker was carried out using PCR-RFLP analysis in 309 Hanwoo steers in order to evaluate their association with carcass traits. The g.166A $>$ G SNP marker showed a significant effect on the marbling score. Animals with the GG genotype had higher marbling score compared with AA and AG genotypes $(p<0.05)$. This SNP marker also showed a significant additive effects for the marbling score $(p<0.05)$. These results suggest that the EDG1 gene can be used as a molecular marker for DNA marker-assisted selection in order to increase the levels of the marbling score in Hanwoo.
\end{abstract}

Key words: EDG1, marbling score, SNP, meat quality, Hanwoo

\section{Introduction}

Generally, marbling means the amount and distribution of intramuscular fat in a cross section of musculus longissimus muscle (Cameron et al., 1994). In particular, eating quality traits such as taste, juiciness and tenderness of meat are influenced by the amount of intramuscular fat (Platter et al., 2005; Chung et al., 2008). High levels of marbling improve the palatability and acceptability of beef by affecting the taste and tenderness of the meat (Busboom et al., 1993; Boylston et al., 1995; Matsuishi et al., 2001; Yamada et al., 2009a). In addition, marbling is the most economically important meat quality trait in beef industry of Korea because carcass value is primarily determined by the degree of marbling. Therefore, the challenge to the beef cattle industry in Korea is the production of meat with higher marbling score. However, meat quality traits such as marbling can usually only be measured post-slaughter, so that making progress using direct measurements is difficult (Gill et al., 2010). The

\footnotetext{
*Corresponding author: Eui-Ryong Chung, Division of Animal Science and Resources, College of Life Science and Natural Resources, Sangji University, Wonju 220-702, Korea. Tel: 82-33730-0541, Fax: 82-33-730-0541, E-mail: erchung@sangju.ac.kr
}

accumulation of intramuscular fat is largely influenced by the genetic background of cattle, as well as their age and nutrition (Wang et al., 2009). Although physiological regulation and genetic controls of carcass and meat quality traits are under the control of multiple genes, there is considerable evidence that specific gene or gene markers have very large effects on carcass traits (Warner et al., 2010). Some previous studies have reported candidate genes associated with marbling in beef cattle breeds. Currently, the leptin, thyroglobulin, DGAT1 gene and growth hormone genes have been identified to affect marbling deposition. Thus, it is important to identify gene markers that can be used as early biomarkers for the prediction of marbling development in beef cattle. DNA markers found in various candidate genes linked to economically important traits have been incorporated into commercially available DNA marker tests for meat quality in beef cattle (Gill et al., 2010; Van Eenennaam et al., 2007).

The endothelial differentiation sphingolipid G-proteincoupled receptor 1 (EDG1) gene, which is known to be involved in blood vessel formation (Liu et al. 2000), has been previously shown to possess higher expression levels in a high-marbled steer group than in low-marbled steer group in musculus longissimus muscle in Japanese Black cattle (Sasaki et al., 2006a; Sasaki et al., 2006b). In 
addition, the EDG1 gene is located within genomic region of a quantitative trait locus (QTL) for marbling on bovine chromosome 3 (Sasaki et al., 2006b; Yamada et al., 2006). Therefore, the EDG1 gene has been regarded as a positional and functional candidate for the gene responsible for marbling. Recently, previous studies have reported that a SNP marker of the bovine EDG1 gene was associated with beef marbling score in the Japanese Black beef cattle population (Sukegawa et al., 2010; Yamada et al., 2009a; Yamada et al., 2009b). However, it is necessary to investigate whether this association could be confirmed in other populations and breeds, which is essential for the development of DNA marker tests and proper commercialization of the markers (Barendse et al., 2009). In view of the lack of information regarded potential uses of molecular markers for marbling in Hanwoo, the objective of this study was to identify SNP marker in the EDG1 gene and to evaluate the effect of the EDG1 marker gene on carcass traits in Hanwoo population.

\section{Materials and Methods}

\section{Animals and carcass data}

We used 309 unrelated steers produced in a progeny testing program of National Institute of Animal Science (NIAS) of Korea. The pedigree record of steers was produced from 52 sires collected by the Korean Animal Improvement Association. All steers were reared under the tightly controlled conditions of the feeding program in the Daekwanryeong and Namwon branch stations of NIAS so as to exclusive variations due to feeding, management and age at slaughter. They were weaned at a mean age of 3 mon and fed with $30 \%$ concentrates and $70 \%$ roughage until 6 mon of age. After 6 mon of age, they were housed in a tie-stall and fed ad libitum on roughage and concentrate diet during performance testing period. Live weights were determined before slaughter. The animals were slaughtered at 24 mon of age with mean live weight of $538.2 \pm 51.56 \mathrm{~kg}$ at a commercial slaughter house. The carcass phenotypes analyzed in the current study included live weight (LW), carcass weight (CW), dressing percentage (DP), backfat thickness (BFT), Longissimus dorsi (ribeye) muscle area (LMA), and marbling score (MS). The carcasses were chilled for $24 \mathrm{~h}$ at $4^{\circ} \mathrm{C}$. Meat yield grades for carcass were determined by cold carcass weight. Meat samples were collected from 13th thoracic rib to the first lumbar vertebrae of the steers within $24 \mathrm{~h}$ of slaughter and evaluated according to the Animal Product Grading System of Korea. The BFT and
LMA were measured between the 12th and 13th rib interface. The MS was scored on a scale from 1 (worst) to 7 (best) with a cross section of the longissimus muscle at the 12th to 13th rib interface according to the Korean Beef Marbling Standard. The number of records, overall means and standard deviations (SD) of phenotypic values are shown in Table 1. For each animal, genomic DNA was extracted from whole blood by using Salting-out protocol (Miller et al., 1988). The DNA sample was suspended in TE buffer $(10 \mathrm{mM}$ Tris- $\mathrm{HCl}, \mathrm{pH} 7.4 ; 1 \mathrm{mM}$ EDTA) and stored at $-20^{\circ} \mathrm{C}$ until analysis.

\section{Sequencing, cloning and SNP discovery}

PCR primers for amplification and sequencing analysis were designed based on the DNA sequence of the bovine EDG1 gene from GenBank accession no. NC_007301.5 (from Btau4.6.1) that included 5'-UTR to screen SNP in the EDG1 gene from Hanwoo. We have amplified a fragment (691 bp) at the 5' -UTR region of the EDG1 gene. The EDG1 gene was amplified by PCR using the following primers: forward primer (5'-CTAAAGAAGCCACTCAGCCTCA-3') and reverse primer (5'-GTGGAATTCTCAAGACCACAGC-3'). The PCR reaction was performed in a $20 \mu \mathrm{L}$ reaction mixture containing $10 \mathrm{pM}$ of each primer, $1.5 \mathrm{mM} \mathrm{MgCl}, 2.5 \mathrm{mM}$ of each dNTP and 1.5 unit of Taq DNA polymerase (Gibco BRL, Grand Island, NY), 10X reaction buffer and $50 \mathrm{ng}$ of genomic DNA as template. The PCR conditions were $94^{\circ} \mathrm{C}$ for 5 min, followed by 35 cycles of $94^{\circ} \mathrm{C}$ for $30 \mathrm{~s}, 51^{\circ} \mathrm{C}$ for 30 $\mathrm{s}$, and $72^{\circ} \mathrm{C}$ for $45 \mathrm{~s}$, with a final extension at $72^{\circ} \mathrm{C}$ for 5 min (MJ Research, PT-200, MA). PCR-generated fragments were identified on $2 \%$ agarose gel. The fragments were inserted into pGEM $\mathrm{T}$ easy vectors for blue and white selection with DH10B competent cells. Positive clones were sequenced using an automated DNA

Table 1. Means, standard deviations (SD), and extreme values of phenotypic values measured on each trait in Hanwoo population

\begin{tabular}{lccrr}
\hline \hline \multicolumn{1}{c}{ Traits } & $\begin{array}{c}\text { No. of } \\
\text { animals }\end{array}$ & Mean \pm SD & Minimum & Maximum \\
\hline $\mathrm{LW} / \mathrm{kg}$ & 309 & $538.22 \pm 51.56$ & 390.00 & 690.00 \\
$\mathrm{CW} / \mathrm{kg}$ & 309 & $307.29 \pm 33.55$ & 212.00 & 401.00 \\
$\mathrm{DP} / \%$ & 309 & $57.10 \pm 1.64$ & 52.60 & 62.40 \\
$\mathrm{BFT} / \mathrm{cm}$ & 309 & $0.70 \pm 0.28$ & 0.20 & 1.80 \\
$\mathrm{EMA} / \mathrm{cm}^{2}$ & 309 & $75.46 \pm 8.19$ & 54.00 & 97.00 \\
$\mathrm{MS} / 1-7$ & 309 & $2.35 \pm 1.42$ & 1.00 & 7.00 \\
\hline
\end{tabular}

$\mathrm{LW}$, live weight; $\mathrm{CW}$, carcass weight; DP, dressing percentage; BFT, backfat thickness; EMA, M. Longissimus dorsi area; MS, marbling score. 
sequencer (ABI 3130XL, Perkin-Elmer, USA) with BigDye 3.1 reagents.

\section{SNP genotyping using PCR-RFLP}

For association with carcass phenotypes, genotyping of g.166A $>$ G SNP (numbering according to GenBank accession no. NC_007301.5, from Btau4.6.1) within the 5'UTR of the EDG1 gene was performed by a PCR-RFLP (restriction fragment length polymorphism) method. Restriction enzyme $M s c$ I for the g.166A $>$ G SNP was determined using the SEQMAN program of DNAstar version 6.0. To genotype individual animals, RFLP analysis was performed using $10 \mu \mathrm{L}$ of PCR products and 2 $\mathrm{U}$ of restriction enzyme and incubated at $37^{\circ} \mathrm{C}$ for $3 \mathrm{~h}$. The digested DNA fragments were separated on $2 \%$ agarose gel by electrophoresis with $1 \mathrm{X}$ TBE buffer. The gels were stained with ethidium bromide and the fragments were visualized using a UV transilluminator (Ultra Rum Inc, USA). To define each genotype according to band patterns, the PCR products of different RFLP type corresponding to each genotype were sequenced and analyzed for nucleotide changes.

\section{Statistical analysis}

Allele and genotype frequencies of SNPs and Hardy-
Weinberg equilibrium were estimated and tested using PROC ALLELE (SAS Inst. Inc., NC). Associations between SNP genotypes of the EDG1 gene and carcass traits were analyzed with the following liner mixed model using the MIXED procedure of SAS.

$$
Y_{i j k l m}=\mu+S_{i}+Y S_{j}+S P_{k}+A_{l}+G_{m}+e_{i j k l m}
$$

Where, $Y_{i j k l m}$ is the carcass phenotype, $\mu$ is its overall mean, $S_{i}$ is the effect of sire, $Y S_{i}$ is the effect of year and season at calving, $S P_{k}$ is the effect of slaughter place, $A_{l}$ is the effect of age at slaughter (covariate), $G_{m}$ is the fixed effect of SNP genotype, and $e_{i j k l m}$ is the random residual. Significant differences among mean values of different genotypes were calculated using Duncan's multiple range test, and determined to be statistically significant at $p<0.05$.

The additive and dominance effects were also estimated using REG procedure of SAS version 9.2, where the additive effect was denoted as $-1,0$, and 1 for $\mathrm{AA}, \mathrm{AG}$, and $\mathrm{GG}$, respectively, and the dominance effect was denoted as $1,-2$, and 1 for AA, AG, and GG, respectively.

\section{Results}

\section{SNP identification in the Hanwoo EDG1 gene}

For SNP detection of the EDG1 gene in Hanwoo, a

Bovine Chromosome 3 - NC_007301.5 (from Btau4.6.1)
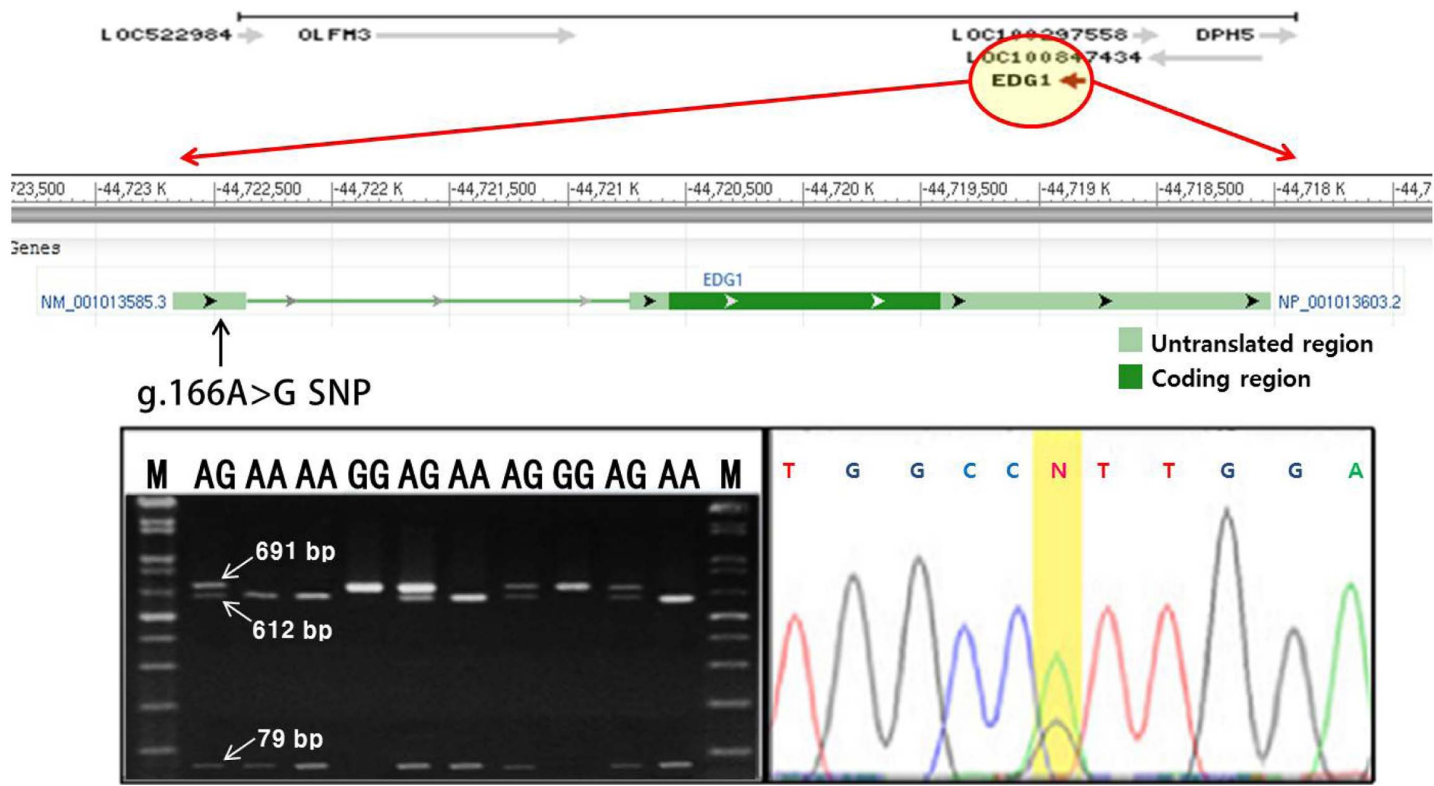

Fig. 1. Gene map position of SNP, PCR-RFLP analysis, and sequence chromatogram showing the nucleotide variant of the 5'UTR of EDG1 gene identified in Hanwoo. PCR-RFLP patterns showing different genotypes of the g.166A>G SNP of EDG1 gene. Lanes M: molecular size marker. The different genotypes at the SNP are indicated at the top of each lane. The PCR products of EDG1 gene were digested by the $M s c \mathrm{I}$ restriction enzyme. The G allele remained uncut at 691 bp because of the absence of a $M s c \mathrm{I}$ recognition site, while the A allele, characterized by a $M s c \mathrm{I}$ restriction site, was cleaved into two fragments of 79 and 612 bp. All three possible SNP genotypes, AA, AG and GG, were observed in Hanwoo population. 
mixed DNA sample from 100 unrelated Hanwoo steers was amplified and sequenced. In this study, one SNP was identified in the EDG1 gene by sequencing analysis: an A to $G$ substitution located 166 bp downstream of the transcription initiation site in the 5'-UTR (g.166A>G).

\section{SNP genotyping by using PCR-RFLP method}

Genotyping of the SNP located at position g.166A $>\mathrm{G}$ within the 5'-UTR of the EDG1 gene was performed by a PCR-RFLP method (Fig. 1). PCR fragments (691 bp) containing the SNP site were amplified and digested with MscI enzyme. The $\mathrm{G}$ allele remained uncut at $691 \mathrm{bp}$ because of the absence of a $M s c$ I recognition site, while the A allele, characterized by a $M s c$ I restriction site, was cleaved into two fragments of 79 and $612 \mathrm{bp}$. All three possible SNP genotypes, AA, AG and GG, were observed in Hanwoo population. The AA homozygotes, AG heterozygotes, and GG homozygotes resulted in two bands (612 and $79 \mathrm{bp}$ ), three bands (691, 612 and $79 \mathrm{bp}$ ), and one band (691 bp), respectively. The allele and genotype frequencies are shown in Table 2. In g. 166A $>$ G SNP, the frequency of allele A (59.1\%) was slightly higher than that of allele $\mathrm{G}(40.9 \%)$. The genotype frequencies were as follows: $33.9 \% \mathrm{AA}, 50.2 \% \mathrm{AG}$, and $15.9 \% \mathrm{GG}$ for the g.166A $>$ G SNP, and observed genotype distributions were in good agreement with those expected according to the Hardy-Weinberg equilibrium in this population. The
Hanwoo population also expressed relatively high heterozygosity value $(0.607)$ for the SNP.

\section{Association analysis of gene-specific SNP marker with carcass traits}

The results of the g. $166 \mathrm{~A}>\mathrm{G}$ SNP marker association analysis are presented in Table 3. The SNP marker of g. $166 \mathrm{~A}>\mathrm{G}$ was significantly associated with the MS. The $\mathrm{G}$ allele showed a significant increasing effects on MS. Animals with the GG genotype had higher MS than animals with AA and AG genotypes $(p<0.05)$. This SNP marker also showed a significant additive effects for the MS $(p<0.05)$. No significant association, however, was detected between any of the SNP genotype and other carcass traits measured in this study.

\section{Discussion}

Marbling defined by the amount and distribution of intramuscular fat is an economically important trait of beef cattle in Korea. The marbling is generally considered to increase juciness and tenderness of meat, and therefore to have a positive association with eating quality (Gutierrez-Gil et al., 2008; Wood et al., 1995). A better knowledge of the molecular mechanism of marbling is important as it may generate new opportunities for more effective marker assisted selection, leading to economic

Table 2. Genotype and allele frequencies for SNP marker of the EDG1 gene in Hanwoo population

\begin{tabular}{|c|c|c|c|c|c|c|c|c|c|}
\hline \multirow{2}{*}{ SNP marker } & \multicolumn{5}{|c|}{ Frequencies (\%) } & \multirow{2}{*}{$\mathrm{He}^{1)}$} & \multirow{2}{*}{$\mathrm{PIC}^{2)}$} & \multicolumn{2}{|c|}{$\mathrm{HWE}^{3)}$} \\
\hline & \multicolumn{3}{|c|}{ SNP genotype } & \multicolumn{2}{|c|}{ SNP allele } & & & $\chi^{2}$ & $p$-value \\
\hline \multirow{2}{*}{ g. $166 \mathrm{~A}>\mathrm{G}$} & $\mathrm{AA}$ & $\mathrm{AG}$ & GG & A & G & \multirow{2}{*}{0.607} & \multirow{2}{*}{0.531} & \multirow{2}{*}{0.429} & \multirow{2}{*}{0.807} \\
\hline & 33.9 & 50.2 & 15.9 & 59.1 & 40.9 & & & & \\
\hline
\end{tabular}

${ }^{1)}$ Heterozygosity

${ }^{2)}$ Polymorphic information content

${ }^{3)}$ Hardy-Weinberg equilibrium

Table 3. Effect of the EDG1 g.166 A>G SNP genotype on carcass traits in Hanwoo population

\begin{tabular}{|c|c|c|c|c|c|c|}
\hline \multirow{2}{*}{ Traits } & \multicolumn{3}{|c|}{ SNP genotype (mean \pm SE) } & \multirow{2}{*}{$p$-value } & \multicolumn{2}{|c|}{ Genetic effect (mean \pm SE) } \\
\hline & $\mathrm{AA}(\mathrm{n}=105)$ & $\mathrm{AG}(\mathrm{n}=155)$ & GG $(n=49)$ & & Additive & Dominance \\
\hline $\mathrm{LW} / \mathrm{kg}$ & $549.411 \pm 6.041$ & $543.116 \pm 5.677$ & $532.000 \pm 22.281$ & 0.619 & $17.411 \pm 23.086$ & $-4.822 \pm 25.728$ \\
\hline $\mathrm{CW} / \mathrm{kg}$ & $313.661 \pm 3.778$ & $313.116 \pm 3.550$ & $308.400 \pm 13.932$ & 0.935 & $5.261 \pm 14.436$ & $-4.172 \pm 16.087$ \\
\hline $\mathrm{DP} / \%$ & $57.623 \pm 0.252$ & $57.925 \pm 0.196$ & $8.574 \pm 0.293$ & 0.741 & $0.384 \pm 0.325$ & $-0.006 \pm 0.527$ \\
\hline $\mathrm{BFT} / \mathrm{cm}$ & $0.732 \pm 0.035$ & $0.750 \pm 0.033$ & $0.780 \pm 0.131$ & 0.894 & $-0.047 \pm 0.135$ & $0.010 \pm 0.151$ \\
\hline $\mathrm{LMA} / \mathrm{cm}^{2}$ & $77.102 \pm 0.980$ & $76.298 \pm 0.921$ & $76.400 \pm 3.615$ & 0.834 & $0.702 \pm 3.746$ & $0.905 \pm 4.174$ \\
\hline MS/1-7 & $3.014 \pm 0.200^{\mathrm{b}}$ & $3.090 \pm 0.188^{b}$ & $4.800 \pm 0.737^{\mathrm{a}}$ & 0.037 & $-1.785 \pm 0.764 *$ & $1.632 \pm 0.851$ \\
\hline
\end{tabular}

LW, live weight; CW, carcass weight; DP, dressing percentage; BFT, backfat thickness; LMA, Longissimus dorsi muscle area; MS, marbling score

*Effect was significant at $p<0.05$.

${ }^{\mathrm{a}, \mathrm{b}}$ Within a row, means with different superscript letter significantly differ $(p<0.05)$. 
benefits to the beef industry (Yamada et al., 2009b). Recent developments in genomic analysis have made it possible to identify specific gene or gene markers that influence economic traits including carcass and meat quality traits in livestock. Although many meat quality traits have generally been assumed to be under the control of multiple genes, there is considerable evidence that single genes account for a relatively large amount of variation for some traits (Burrow et al., 2001; Warner et al., 2010). Therefore, gene markers that are significantly associated with certain traits of interest are very useful by applying DNA markers through marker-assisted selection. Genes that regulate metabolism and energy partitioning have the potential to influence economically important traits in farm animals, as do polymorphisms within these genes (Sherrman et al., 2008). Several our previous studies have reported that SNPs in the leptin (Shin and Chung, 2007a), thyroglobulin (Shin and Chung, 2007b), carboxypeptidase E (Shin and Chung, 2007c), C/ EBP $\alpha$ (Shin et al., 2007), and FABP4 (Shin et al., 2012) genes were associated with marbling score in Hanwoo. Thus, our present study will be the report to show additional candidate gene associated with marbling score in Hanwoo population.

Sphingolipid signaling pathways have been implicated in many critical cellular events. Sphingosine-1-phosphate (SPP), a sphingolipid metabolite found in high concentrations in platelets and blood, stimulates members of the endothelial differentiation gene (EDG) family of G protein-coupled receptors and triggers diverse effects, including cell growth, survival, migration, and morphogenesis (Liu et al., 2000). The endothelial differentiation sphingolipid G-protein-coupled receptor 1 (EDG1) gene as lipid receptors plays an important role in vascular maturation and shows that sphingolipid signaling is essential during mammalian development (Liu et al., 2000).

In this study, we identified one SNP within the EDG1 gene and the g.166A $>$ G SNP markers were evaluated with respect to their effects on several carcass and meat quality traits in Hanwoo. A significant difference $(p<0.037)$ was obtained for marbling score between SNP genotypes of g.166A $>\mathrm{G}$ marker but not for other measured traits. The animals with homozygous genotype GG showed a significantly higher marbling score compared with those of heterozygous genotype AG or homozygous genotype AA. The results of this study contribute to the information available on genetic markers for meat quality, especially intramuscular fat content. Therefore, the g.166A $>\mathrm{G}$ SNP marker of EDG1 gene could be used for substantial improvement of marbling in Hanwoo. However, this EDG1 SNP marker did not affect other traits such as live weight, carcass weight, dressing percentage, backfat thickness, and M. Longissimus dorsi area. Yamada et al. (2009a) first identified two SNPs in the 5'-UTR and the 3'-UTR of EDG1 gene, referred to as c.-312A $>\mathrm{G}$ and c. $* 446 \mathrm{G}>\mathrm{A}$, respectively, and analysed association of the SNPs with marbling and subcutaneous fat thickness in Japanese Black beef cattle. The g.166A $>$ G SNP identified in this study is identical to previously reported SNP (c.-312A $>$ G) in Japanese Black cattle. They also reported that the EDG1 SNP markers were associated marbling score level in a Japanese Black beef cattle population, with the $\mathrm{G}$ allele of the SNP being associated with a high level of marbling score. These results were consistent with this study. The 5'-UTRs within the genomic regions are involved in many post-transciptional regulatory pathways that control mRNA localisation, stability, translation efficiency, and initiation of protein synthesis (Cheong et al., 2006; Shabalina and Spiridonov, 2004). The posttranscriptional events play an important, yet incompletely understood, role in regulatory gene expression and cellular behaviour; many of the identified cis-acting elements for translational regulation occur within the UTR (Conklin et al., 2002). The EDG1 gene has been previously shown to possess expression difference in musculus longissimus muscle between high-marbled and low-marbled steer groups, and to be located within genomic region of QTL for marbling. These finding suggest that the SNPs within the 5'-UTR of EDG1 gene are associated with variations in the intramuscular fat deposition of musculus longissimus muscle. Therefore, EDG1 gene-specific SNP identified in this study may be a potential candidate DNA marker for marbling of Hanwoo. In conclusion, we have demonstrated that the SNP marker of EDG1 gene is significantly associated with marbling score and will be useful for effective marker-assisted selection to increase the levels of marbling in Hanwoo. Further studies are will be needed to confirm the associated effect on other populations and to detect additional SNP markers of EDG1 gene in Hanwoo.

\section{Acknowledgements}

This study was supported by Sangji University Research Fund, 2010

\section{References}

1. Barendse, W., Bunch, J. R., and Harrison, E. B. (2009) Vari- 
ation at CPE but not CEBPA appears to be associated with intramuscular fat deposition in the longissimus muscle of cattle. Anim. Prod. Sci. 49, 558-562.

2. Boylston, T. D., Morgan, S. A., Johnson, K. A., Busboom, J. R., Wright, R. W. Jr., and Reeves, J. J. (1995) Lipid content and composition of Wagyu and domestic breeds of beef. $J$. Agric. Food Chem. 43, 1202-1207.

3. Burrow, H. M. (2001) Variances and covariances between productive and adaptive traits and temperament in a composite breed of tropical beef cattle. Livest. Prod. Sci. 70, 213233.

4. Busboom, J. R., Jeremiah, L. E., Gibson, L. L., Johnson, K. A., Gaskins, C. T., Reeves, J. J., and Wright, R. W. Jr. (1993) Effects of biological source on cooking and palatability attributes of beef produced for the Japanese market. Meat Sci. 35, 241-258.

5. Cameron, P. J., Zembayashi, M., Lunt, D. K., Mitsuhashi, T., Mitsumoto, T., Ozawa, S., and Smith, S. B. (1994) Relationship between Japanese beef marbling standard and intramuscular lipid in the M. longissimus thoracis of Japanese Black and American Wagyu cattle. Meat Sci. 38, 361-364.

6. Cheong, H. S., Yoon, D. H., Kim, L. H., Park, B. L., Choi, Y. H., Chung, E. R., Cho, Y. M., Park, E. W., Cheong, I. C., Oh, S. J., Yi, S. G., Park, T., and Shin, H. D. (2006) Growth hormone-releasing hormone (GHRH) polymorphisms associated with carcass traits of meat in Korean cattle. BMC Genet. 3, 35 .

7. Chung, E. R., Shin, S. C., Shin, K. H., and Chung K. Y. (2008) SNP discovery in the leptin promoter gene and association with meat quality and carcass traits in Korean cattle. AsianAust. J. Anim. Sci. 12, 1689-1695.

8. Conklin, D., Jonassen, I., Aasland, R., and Taylor, W. R. (2002) Association of nucleotide patterns with gene function classes: application to human 3' untranslated sequences. Bioinformatics. 18, 182-189.

9. Gill, J. L., Bishop, S. C., McCorquodale, C., Williams, J. L., and Wiener, P. (2010) Associations between single nucleotide polymorphisms in multiple candidate genes and carcass and meat quality traits in a commercial Angus-cross population. Meat Sci. 86, 985-993.

10. Gutierrez-Gil, B., Wiener, P., Nate, G. R., Burton, D., Gill, J. L., Wood, J. D., and Williams, J. L. (2008) Detection of quantitative trait loci for meat quality traits in cattle. Anim. Genet. 39, 51-61.

11. Liu, Y., Wada, R., Yamashita, T., Mi, Y., Deng, C. X., Hobson, J. P., Rosenfeldt, H. M., Nava, V. E., Chae, S. S., Lee, M. J., Liu, C. H., Hla, T., Spiegel, S., and Proia, R. L. (2000) Edg-1, the G protein-coupled receptor for sphingosine-1phosphate, is essential for vascular maturation. J. Clin. Invest. 106, 951-961.

12. Matsuishi, M., Fujimori, M., and Okitanim, A. (2001) Wagyu beef aroma in Wagyu (Japanese Black cattle) beef preferred by the Japanese over imported beef. Anim. Sci. J. 72, 498504.

13. Miller, S. A., Dykes, D. D., and Polesky, H. F. (1988) A simple salting out procedure for extracting DNA from human nucleated cells. Nucl. Acids Res. 16, 1215.

14. Platter, W. J., Tatum, J. D., Belk, K. E., Koontz, S. R., Chapman, P. L., and Smith, G. C. (2005) Effects of marbling and shear force on consumers' willingness to pay for beef strip loin steaks. J. Anim. Sci. 83, 890-899.

15. Sasaki, Y., Nagai, K., Nagata, Y., Doronbekov, K., Nishimura, S., Yoshioka, S., Fujita, T., Shiga, K., Miyake, T., Taniguchi, Y., and Yamada, T. (2006a) Exploration of genes showing intramuscular fat deposition-associated changes in musculus longissimus muscle. Anim. Genet. 37, 40-46.

16. Sasaki, Y., Yamada, T., and Miyake, T. (2006b) Quantitative and molecular genetic approaches for the improvement of carcass traits in the Wagyu cattle. In: 8th World Congress on Genetics Applied to Livestock Production, Session no. 1301. Belo Horizonte, Minas Gerais, Brazil.

17. Shabalina, S. A. and Spiridonov, N. A. (2004) The mammalian transcriptome and the function of non-coding DNA sequences. Genome Biol. 5, 105.

18. Sherman, E. L., Nkrumah, J. D., Murdoch, B. M., Li, C., Wang, Z., Fu, A., and Moore, S. S. (2008) Polymorphisms and haplotypes in the bovine neuropeptide $\mathrm{Y}$, growth hormone receptor, ghrelin, insulin-like growth factor, and uncoupling protains 2 and 3 genes and their associations with measures of growth, performance, feed efficiency, and carcass merit in beef cattle. J. Anim. Sci. 86, 1-16.

19. Shin, S. C. and Chung, E. R. (2007a) Association of SNP marker in the leptin gene with carcass and meat quality traits in Korean cattle. Asian-Aust. J. Anim. Sci. 20, 1-6.

20. Shin, S. C. and Chung, E. R. (2007b) Association of SNP marker in the thyroglobulin gene with carcass and meat quality traits in Korean cattle. Asian-Aust. J. Anim. Sci. 20, 172177.

21. Shin, S. C. and Chung, E. R. (2007c) SNP detection carboxypeptidase $\mathrm{E}$ gene and its association with meat quality and carcass traits in Korean cattle. Asian-Aust. J. Anim. Sci. 20, 328-333.

22. Shin, S. C., Kang, M. J., and Chung, E. R. (2007) Identification of a novel SNP associated with meat quality in $\mathrm{C} / \mathrm{EBP} \alpha$ gene of Korean cattle. Asian-Aust. J. Anim. Sci. 20, 466-470.

23. Shin, S. C., Heo, J. P., and Chung, E. R. (2012) Genetic variants of the FABP4 gene are associated with marbling scores and meat quality grades in Hanwoo (Korean cattle). Mol. Biol. Rep. 39, 5323-5330.

24. Sukegawa, S., Miyake, T., Takahagi, Y., Murakami, H., Morimatsu, F., Yamada, T., and Sasaki, Y. (2010) Replicated association of the single nucleotide polymorphism in EDG1 with marbling in three general populations of Japanese Black beef cattle. BMC Res. Notes. 3, 66.

25. Van Eenennaam, A. L., Li, J., Thallman, R. M., Quaas, R. L., Dikeman, M. E., Gill, C. A., Franke, D. E., and Thomas, M. G. (2007) Validation of commercial DNA tests for quantitative beef quality traits. J. Anim. Sci. 85, 891-900.

26. Wang, Y. H., Bower, N. I., Reverter, A., Tan, S. H., De Jager, N., Wang, R., McWilliam, S, M., Café, L. M., Greenwood, P. L., and Lehnert, S. A. (2009) Gene expression patterns during intramuscular fat development in cattle. J. Anim. Sci. 87, 
119-130.

27. Warner, R. D., Greenwood, P. L., Pethick, D. W., and Ferguson, D. M. (2010) Genetic and environmental effects on meat quality. Meat Sci. 86, 171-183.

28. Wood, J. D., Nute, G. R., Fursey, G. A. J., and Cuthbertson, A. (1995) The effect of cooking conditions on the eating quality of pork. Meat Sci. 40, 127-135.

29. Yamada, T., Itoh, M., Nishimura, S., Taniguchi, Y., Miyake, T., Sasaki, S., Yoshioka, S., Fujita, T., Shiga, K., Morita, M., and Sasaki, Y. (2009a). Association of single nucleotide polymorphisms in the endothelial differentiation sphingolipid G-proteincoupled receptor 1 gene with marbling in Japanese Black beef cattle. Anim. Genet. 40, 209-216.
30. Yamada, T., Sasaki, S., Sukegawa, S., Miyake, T., Fujita, T., Kose, H., Morita, M., Takahagi, Y., Murakami, H., Morimatsu, F., and Sasaki, Y. (2009b) Novel SNP 5' flanking region of EDG1 associated with marbling in Japanese Black beef cattle. Anim. Sci. J. 80, 486-489.

31. Yamada, T., Taniguchi, Y., Nishimura, S., Yoshioka, S., Takasuga, A., Sugimoto, Y., and Sasaki, Y. (2006) Radiation hybrid mapping of genes showing intramuscular fat deposition-associated expression changes in bovine musculus longissimus muscle. Anim. Genet. 37, 184-185.

(Received 2012.8.17/Revised 2012.10.23/Accepted 2012.11.28) 